\title{
O PROCESSO DE MERCANTILIZAÇÃO DAS INSTITUIÇÕES DE EDUCAÇÃO SUPERIOR: UM PANORAMA DO DEBATE NOS EUA, NA EUROPA E NA AMÉRICA LATINA
}

\author{
Milena Pavan Serafim*
}

Recebido: abr. 2011

Aprovado: abr. 2011

* Doutoranda em Política Científica e Tecnológica (2008), UNICAMP, Bolsista da: Fundação de Amparo
à Pesquisa do Estado de São Paulo (FAPESP). Mestre em Política Científica e Tecnológica (2006-2008),
UNICAMP. Campinas, SP, Brasil. E-mail: milenaserafim@gmail.com

Resumo: O presente artigo apresenta as características gerais dos debates sobre o processo de mercantilização das instituições de educação superior nos EUA, na Europa e na América Latina. Parte da compreensão de que esse processo foi aprofundado e, em grande medida, acelerado pela "nova fase do capitalismo" e pelos reflexos das mudanças ideológicas mais amplas ligadas à ascensão do neoliberalismo. Ao visitar as questões debatidas sobre o processo de mercantilização da educação nesses países, o trabalho ressalta a dimensão ideológica por trás dele e contribui com os numerosos trabalhos acadêmicos que buscam contrapô-lo e que oferecem elementos para a reorientação da educação superior.

Palavras-chave: Processo de mercantilização. Instituições de educação superior. EUA. América Latina. Europa.

\section{THE MERCANTILIZATION PROCCESS OF HIGHER EDUCATION INSTITUTIONS: AN OVERVIEW OF THE DEBATE IN THE U.S., EUROPE AND LATIN AMERICA}

Abstract: This paper presents the general characteristics of the debate concerning the mercantilization proccess of higher education institutions in the USA, Latin America and Europe. It departs from the understanding that this proccess has been deepened and, to a great extent, has been accelerated during the current phase of capitalism and by the impacts of the broad ideological changes related to the rise of neoliberalism. By addressing the main questions regarding the mercantilization proccess in these countries, the paper stresses the ideological aspects behind it and contributes to the numerous works that seek to challenge it in the direction of another orientation for higher education.

Key words: Mercantilization process. Higher education institutions. USA. Latin America. Europe.

\section{INTRODUÇÃO}

O final do século XX representou um momento de importantes transformações no sistema capitalista mundial. Acompanhando essas transformações, a educação superior passou - e ainda segue passando - por um período de redefinição das suas funções. Esta redefinição vincula-se às mudanças impostas pelo processo de globalização econômica que permeia o mundo contemporâneo. A principal redefinição se refere à orientação cada vez mais próxima das instituições de educação superior (IES) à lógica do "mercado". 
A "nova fase do capitalismo" (caracterizada por modelos de produção mais enxutos, financeirização do mercado e redução da participação do Estado na economia, entre outros fatores), reforçada pelo retorno aos fundamentos da antiga doutrina liberal através da ascensão do neoliberalismo ${ }^{1}$, passou a subsidiar, em grande medida, essas práticas de aproximação à demanda ou racionalidade do mercado. O processo de influência dessa conjuntura econômica, política e ideológica sobre a educação superior é reconhecido como o principal impacto sofrido por essas instituições desde a sua origem. Esse processo tem sido identificado por diferentes rótulos: nos EUA como "capitalismo acadêmico", na Europa como homogeneização da educação superior e na América Latina como mercantilização e comoditização da educação superior pública. O efeito desse processo mais amplo de mercantilização da educação sobre os sistemas nacionais de educação superior vem sendo retratado em inúmeros trabalhos acadêmicos.

$\mathrm{Na}$ tentativa de contribuir com o debate, este trabalho tem como objetivo apresentar e comparar algumas das principais interpretações acerca do processo de mercantilização da educação superior nos EUA, na Europa e na América Latina. Para isso, ele parte do entendimento de que esse processo se relaciona com mudanças de caráter mais geral, associadas, sobretudo, à emergência do projeto neoliberal.

Vale ressaltar que o trabalho não tem a pretensão de cobrir toda a amplitude do debate, e tampouco de abranger todas as especificidades desse processo nas regiões aqui tratadas. Pretende-se apenas apresentar um panorama das reflexões conduzidas por alguns autores em cada região. Assim, espera-se que, ao abordar diferentes aspectos das discussões a respeito do processo de mercantilização, sistematizando as principais contribuições, este trabalho possa servir como uma espécie de mapa do corrente debate.

Para cumprir esse desafio, o artigo está dividido em cinco sessões, além desta introdução. Na primeira são discutidos os aspectos fundamentais do contexto neoliberal, no qual as transformações das instituições de ensino superior estão inseridas. Tendo em vista que esse trabalho parte do entendimento de que a reforma neoliberal aprofundou a relação das IES com o "mercado", faz-se necessário apresentar os aspectos ideológicos desse contexto. A segunda sessão apresenta o debate sobre o "capitalismo acadêmico" nos EUA. Em seguida, na terceira sessão analisamos o Processo de Bolonha e o movimento de homogeneização dos currículos na Europa. Na quarta sessão, de forma semelhante às

1 Apesar da causalidade entre a nova economia e esse processo de mudança nas estruturas acadêmicas não ser tão linear, são notáveis as implicações dela na academia. 
demais, é discutido o processo de comoditização da educação superior privada e de mercantilização/privatização da educação superior pública na América Latina. Por fim, são apresentadas algumas considerações finais baseadas nas reflexões geradas ao longo do trabalho.

\section{A ONDA NEOLIBERAL E SEUS IMPACTOS}

A década de 1980 representou um momento de transição, sobretudo na esfera política. A vitória do privado sobre o Estado e a esfera pública estava demonstrando sinais no mundo. Esse cenário de alternância de poder derivava da falência do padrão econômico até então vigente. A importância do trabalho assalariado, o contexto monetário internacional e o papel do Estado na economia passaram a ser erodidos. Chesnais (1996) coloca que eram estes três pilares que sustentavam o padrão econômico.

Para Dias (2009), o trabalho assalariado, até os anos 1970, representava a forma predominante de inserção social e acesso à renda. Esse mecanismo, baseado no padrão fordista, criou um ciclo virtuoso de consumo que impulsionou significativamente o crescimento econômico nesse período. No que se refere ao pilar do contexto monetário, o autor ressalta que o sistema financeiro internacional, ainda que desproporcionalmente favorável aos EUA, era relativamente estável e não ameaçava a esfera produtiva. O terceiro pilar - papel do Estado - era pautado no apoio que o Estado desempenhava principalmente a fim de disciplinar o capital privado, fortalecendo as empresas nacionais (embora essa postura não tenha sido igualmente bem-sucedida em todos os países) e atuando em setores importantes, como saúde, educação e infra-estrutura.

A partir de meados da década de 1980, afirma Chesnais (1996), esses três pilares, que garantiam o dinamismo do modelo capitalista anterior, passaram a ser paulatinamente erodidos. O modo de produção fordista cede lugar a modelos mais "enxutos", que se mostraram incapazes de manter o trabalho assalariado como forma fundamental de inserção social e acesso à renda. As instituições internacionais, por sua vez, abandonam o destino de moedas e finanças aos mecanismos de regulação dos próprios mercados. O Estado, debilitado por sucessivas críticas quanto a seu suposto intervencionismo excessivo sobre as questões econômicas, passa a buscar uma nova definição, metamorfoseandose, a fim de atender às exigências do capital, em uma nova fase do capitalismo (DIAS, 2009).

Belluzzo (2006), reforçando Chesnais (1996), afirma que as profundas transformações na economia global no final do século XX foram promovidas por 
três movimentos: pela liberalização financeira e cambial, por conta da mudança nos padrões de concorrência intercapitalista e por causa da alteração das regras institucionais do comércio e do investimento. Além disso, o autor ressalta a crescente imposição da competitividade, gerada pelo processo de globalização, que criou a necessidade de que o capital exista sob a forma "livre" e líquida e, simultaneamente, centralizada.

Os processos mencionados acima, de acordo com Dias (2009), estão naturalmente associados a uma tendência maior que, de fato, constitui a grande transformação da segunda metade da década de 1970 e do início dos anos 1980: a ascensão do neoliberalismo, uma nova manifestação da antiga doutrina liberal ${ }^{2}$.

Os processos que tiveram início a partir de então atuaram no sentido de derrubar o padrão estabelecido no período pós-2 ${ }^{\mathrm{a}}$ Guerra Mundial (Estado de Bem-estar) e reavivar as ambições liberais. Segundo Dias (2009), a ascensão do capital financeiro, ávido por recuperar as perdas infligidas pela sua subordinação à esfera produtiva e sedento por novas formas de valorização, foi talvez um dos principais vetores do fortalecimento do ideário neoliberal. O capital financeiro (norte-americano, sobretudo) se fortaleceu às custas de uma significativa deterioração da condição das economias periféricas e, em outro plano analítico, da classe trabalhadora.

O aumento do desemprego e da inflação, a queda da arrecadação tributária, o aumento dos gastos sociais e a baixa efetividade das políticas keynesianas nos países centrais denunciavam o início de uma grave crise de acumulação do capital. Em um contexto no qual as estratégias convencionais se mostraram insuficientes para superar a crise, respostas alternativas tiveram que ser buscadas. O discurso do livre-mercado e do assédio do capital financeiro e das grandes corporações ganhou corpo. Dias (2009) ressalta que foi sob a égide desses interesses que se ergueu um novo padrão de acumulação e - em muitos casos - um novo modelo de desenvolvimento, pautado pelo ideário neoliberal.

Assim, de acordo com Harvey (2007), a difusão das ideias neoliberais pode ser interpretada como um projeto

utópico com a finalidade de realizar um desenho teórico para a reorganização do capitalismo internacional ou, ainda, como um projeto político para restabelecer as condições para a acumulação de capital e restaurar o poder das elites econômicas (HARVEY, 2007, p. 24).

2 Ver mais sobre isso em Polanyi (2000). 
Diferentemente da profunda repulsa à intervenção estatal que pregavam os liberais, os neoliberais reconhecem que a economia não pode prescindir completamente do Estado. A esfera de atuação estatal se limita, conforme detalharemos no item seguinte, a espaços nos quais o setor privado não tem condições ou interesse de atuar (DIAS, 2009).

A doutrina neoliberal é caracterizada fundamentalmente pela primazia das liberdades individuais sobre os direitos coletivos, garantida pelos sistemas de livre-mercado e de livre-comércio. Entretanto, ao contrário dos ideários liberais, o pensamento neoliberal não podia prescindir totalmente do Estado. Passou-se a buscar, então, a construção de um novo Estado, que deveria ser simultaneamente competente na remoção dos obstáculos à acumulação capitalista e incapaz de promover ações radicais que ameaçassem a longevidade do novo padrão que se moldava.

Um marco importante no qual estão respaldados os fundamentos centrais do neoliberalismo (e que serviu como processo norteador da reforma do Estado) remete àquilo que se convencionou chamar de Consenso de Washington. De acordo com Williamson (1992, apud DIAS, 2009), esse marco apresentaria alguns pontos principais, a saber:

i. Disciplina fiscal: déficits orçamentários devem ser reduzidos de modo que possam ser financiados sem que se recorra ao imposto inflacionário, o que frequentemente implica superávit primário elevado e déficit operacional de cerca de $2 \%$ do PIB, no máximo;

ii. Prioridades dos gastos públicos: redirecionar os recursos de áreas que recebem mais do que seu retorno econômico justifica (defesa, administração pública) para áreas que apresentam elevado potencial de retorno econômico, como saúde, educação e infra-estrutura;

iii. Reforma fiscal: aumento da base tributária e corte das taxas tributárias marginais, para estimular incentivos e promover uma maior igualdade de forma horizontal, sem que com isso a progressividade já existente seja comprometida;

iv. Liberalização de financiamento: tem como objetivo final a determinação da taxa de juros pelo mercado. Para tanto, coloca também a necessidade de acabar com os juros privilegiados para devedores privilegiados e a obtenção de uma taxa de juros real positiva e moderada; 
v. Taxa de câmbio: a unificação das taxas de câmbio entre os países deve ser buscada. A taxa deve ser fixada e mantida em um nível suficientemente competitivo;

vi. Liberalização do comércio: restrições quantitativas devem ser substituídas por tarifas que, posteriormente, devem ser progressivamente reduzidas até atingirem um patamar uniformemente baixo;

vii. Investimento externo direto: extinção das barreiras à entrada de firmas estrangeiras, que devem competir com as empresas locais nas mesmas condições;

viii. Privatizações: empresas estatais devem ser privatizadas;

ix. Direito de propriedade: deve ser garantido pela justiça e deve ser disponibilizado ao setor informal.

Segundo Williamson (1992), as orientações gerais desse programa podem ser sintetizadas através de elementos como a prudência macroeconômica, a liberalização microeconômica e a orientação externa das economias. Na América Latina, afirma Moraes (2001), a receita para que os países saíssem da crise da dívida do "antigo regime" invariavelmente previa que fosse estabelecida outra relação entre Estado e mercado, deslocando o primeiro e conferindo importância central ao segundo. Argentina, Chile e Uruguai liberaram o comércio, o sistema financeiro e a conta de capitais e lançaram fracassados programas de estabilização econômica.

O Brasil, assim como os outros países latino-americanos, ao implementar a reforma neoliberal-privatizante - intensificada a partir de 1995 - reconheceu o receituário de ajustes macroeconômicos e de reforma do Estado - em busca do Estado-mínimo - defendido pelos países centrais.

A escolha por esse modelo econômico resultou na reformulação do papel do Estado

seja na atuação como empresário (privatização do setor produtivo estatal), seja na regulação da concorrência inter-capitalista (abertura comercial, produtiva, financeira e tecnológica) e do trabalho (desregulamentação das relações de trabalho e flexibilização do mercado de trabalho) (POCHMANN, 2008, p. 3).

Em suma, pode-se afirmar que o pensamento neoliberal, cujas origens e características principais procuramos apresentar aqui, tem como elemento nuclear, 
embora muitas vezes implícito, a ideia de que ao público deve se sobrepor o privado e ao coletivo deve se sobrepor o individual. Mais que isso, a lógica do mercado passa a ser visto como a "mais" eficiente e eficaz, portanto, adequada às práticas institucionais e organizacionais. As IES passam, portanto, a serem cada vez mais adeptas e inseridas nessa lógica pró-mercado, pró-desburocratização, pró-sistema de avaliação utilitarista e quantitativo, pró-ranking, pró-valorização da relação IES-empresa, pró-flexibilização do trabalho, etc., conforme veremos nos itens a seguir.

\section{O MOVIMENTO NOS EUA: O "CAPITALISMO ACADÊMICO”}

A discussão sobre como a educação superior se transformou nas últimas décadas, acompanhando o processo de globalização econômica e financeira, e sobre como ela tem adquirido uma orientação cada vez mais próxima ao "mercado" não é recente. De fato, Bok (2003) situa essas práticas já no início do século XX nos EUA. Também não são recentes os trabalhos acadêmicos que têm retratado o processo de mercantilização da educação superior observado ao longo das últimas décadas nos EUA.

Contudo, recentemente têm surgido estudos que identificam uma nova tendência ao longo das últimas décadas do século XX e no início do século XXI. De acordo com os autores que têm se ocupado com a análise desse fenômeno a partir dos EUA, as principais mudanças observadas estariam ligadas à emergência do "capitalismo acadêmico", uma fase em que esses processos teriam se institucionalizado dentro das universidades, apresentando reflexos que se estendem do currículo oferecido até a estrutura organizacional das instituições (SLAUGHTER; LESLIE, 1997; SLAUGHTER; RHOADES, 2004).

Esses estudos apresentam, de fato, um conjunto de fundamentos para uma "teoria do capitalismo acadêmico". Essa abordagem centra sua análise na linha nebulosa que separa mercado, Estado e educação superior, assim como nas instituições e nos atores que rodeiam essa fronteira. A base dessa abordagem está nos trabalhos de Foucault (1977, 1980), Mann (1986) e Castells (2000).

Trata-se, de fato, de uma tendência que tem sido verificada com frequência nos EUA, mas com reflexos também em outros países, uma vez que o modelo norte-americano de produção de ciência e tecnologia e de educação superior é importado por diversos países (inclusive pelos latino-americanos). Contudo, as críticas realizadas por estudiosos do tema nos EUA em relação ao modelo de educação superior parecem ter sido ainda pouco absorvidas, intencionalmente ou não, pelos seus pares latino-americanos. 
A tese que apresentam Slaughter e Rhoades (2004) é a de que o engajamento das instituições de ensino superior em atividades associadas ao mercado está se aprofundando. As IES, em particular as faculdades públicas e as universidades que perderam significativamente o suporte do Estado nos últimas décadas, agora desenvolvem, introduzem e comercializam produtos em grande escala no setor privado como uma fonte básica de renda. Atualmente, essas IES estão procurando gerar rendimentos a partir de e para seus núcleos educacionais, de pesquisas e de funções de serviço, abarcando desde a produção de conhecimento (tal como a pesquisa que conduz ao desenvolvimento tecnológico e ao patenteamento de invenções) até os currículos dos cursos e ao ensino (por exemplo, por meio dos materiais de ensino introduzidos no mercado).

Assim, os autores detalham um agressivo engajamento das IES norteamericanas na economia baseada no conhecimento e analisam os esforços dessas em desenvolver, mercantilizar e vender produtos de pesquisa, serviços educacionais e bens de consumo no mercado privado.

Sucintamente, a expressão "capitalismo acadêmico" na nova economia refere-se a um regime que engloba o engajamento de faculdades e universidades pró-mercado na conformação do discurso e desse comportamento pró-mercado no âmbito acadêmico. Slaughter e Rhoades (2004) relacionam essa discussão com os temas sobre o estado neoliberal e a nova economia global estabelecendo, assim, uma intrínseca relação entre organização (no caso, as universidades) e o ambiente social, político e econômico que a encerra. Destacam, em particular, o impacto do projeto neoliberal sobre as atividades - mesmo algumas das mais mundanas - conduzidas pelas universidades.

Ademais do impacto desse projeto sobre as organizações, nota-se que as legislações nacional e internacional (os tratados e os acordos comerciais, por exemplo) contribuíram para o desenvolvimento do Capitalismo Acadêmico na educação superior norte-americana. As legislações analisadas, referentes ao auxílio financeiro aos estudantes e à pesquisa, demonstraram a influência que uma tem sobre a outra e como isso levou a um direcionamento da educação superior no sentido pró-mercado.

Outro aspecto que compõe a teoria passa por reflexões a respeito de como o Estado, o sistema estatal e as políticas institucionais de patentes criam oportunidades e propulsionam o capitalismo acadêmico. Ao analisar o sistema federal e as políticas institucionais de patentes de seis estados norte-americanos, Slaughter e Rhoades (2004) descrevem e explicam a influência poderosa do Estado e de seu sistema e das políticas de patentes na emergência de organizações que tentam aproximar a nova economia das IES. 
A política de patentes revela uma mudança da percepção do conhecimento como bem público para um regime capitalizado. A mudança mais aparente, argumentam Slaughter e Rhoades (2004), pode ser percebida naquelas IES que expandiram sua capacidade de gestão, permitindo, assim, o engajamento dessas na nova economia.

Analisando como essas políticas de patentes se relacionam com a prática dos estudantes e docentes/pesquisadores, ou seja, de que forma essas afetam o desempenho acadêmico desses atores, verifica-se que as regras e regulamentos implantados pelas políticas institucionais de patentes e pelo sistema universitário têm codificado e modificado valores e práticas. Membros da comunidade acadêmica têm sido contratados para identificar e descobrir invenções com potencial gerador de receita que podem ser patenteados. A capacidade gerencial das instituições, fundamental para seu engajamento no capitalismo acadêmico, tem aumentado consideravelmente, conforme mostram Slaughter e Rhoades (2004). Além da interação entre segmentos das universidades e mercado, esses segmentos têm incorporado funções de mercado.

Outro mecanismo adotado nesse processo de mercantilização da educação superior foi aquele referente à propriedade intelectual. Esse mecanismo permitiu que o conhecimento fosse concebido como um material que pode ser legalmente protegido e "empacotado" como se fosse um produto vendido em um mercado convencional. Escritórios que facilitassem a apropriação e venda do conhecimento foram criados dentro das IES.

Outro aspecto importante analisado pelos autores consiste na forma com que os reitores das IES contribuem para o regime de capitalismo acadêmico e, mais que isso, até para o comportamento dos mercados. Um caso emblemático é o da organização Internet 2. Esta se refere a um consórcio não-lucrativo, composta por cerca de 200 universidades e 60 empresas, responsável por acelerar a criação da internet de amanhã. Nesta organização, os reitores de universidades norte-americanas buscam expandir a fronteira entre o setor lucrativo e o não-lucrativo, criando para isso oportunidade comercial para os dois. No caso da Internet, além das universidades e das empresas, o governo federal se tornou parceiro também, subsidiando possíveis mercados lucrativos e não-lucrativos.

A partir da análise dos documentos do sítio eletrônico dessa organização, os autores constataram que os reitores trabalham de forma semelhante a presidentes de corporações e líderes de várias agências governamentais na construção de infra-estrutura de tele-comunicações para a nova economia. As universidades e as corporações seguem uma estrutura de propriedade intelectual que permite 
que cada um lucre com os produtos e os processos derivados da pesquisa publicamente financiada ao construir a infra-estrutura da Internet.

Nesse mesmo sentido, as características e procedimentos adotados pelos comitês encarregados da administração universitária das dez melhores universidades privadas e das dez melhores universidades públicas que recebem a maior parte dos fundos da National Science Foundation (NSF) são semelhantes. Ao analisar esses comitês, pode-se observar que eles estão conectados em uma espécie de rede semi-formal. De forma conjunta, eles escolhem práticas e procedimentos de interação com as necessidades da nova economia. Esse tipo de "lobby" acaba por excluir ainda mais as redes universitárias que não fazem parte dessa pequena instância de decisão ou que tentam resistir a esse processo. E, além disso, essas redes criam uma espécie de emulação das práticas adotadas pelas melhores universidades.

As principais contribuições dos autores que têm se dedicado a explorar as motivações e implicações do capitalismo acadêmico estão, principalmente, no desenvolvimento de fundamentos para uma teoria explicativa da nova economia e da centralização da academia como ator do processo de mercantilização da educação superior. Mais que isso, ele busca desmistificar a academia como "vítima" dos interesses econômicos e de destacar o papel desta como ator dinamizador do processo de mercantilização do conhecimento.

\section{A EUROPA E O PROCESSO DE BOLONHA}

Assim como observado em um amplo conjunto de países, a Europa também passou por importantes transformações na década de 1990. A pujança da globalização e a reestruturação do mercado fizeram com que o plano de uma unificação política e econômica fosse concretizado em 1992 com a criação da Comunidade Europeia ${ }^{3}$ (conhecida mais tarde como União Europeia). O objetivo era fortalecer a região em termos políticos e econômicos, de modo que ela pudesse preservar seu papel protagônico frente às mudanças no cenário mundial. Esse processo, contudo, evocava a necessidade de uma série de ações que abrangeriam desde o estabelecimento de políticas comuns de comércio, como a política agrícola, até uma reforma da educação superior, visando a padronização de normas comuns aos países membros da União Européia.

Da prerrogativa de que era necessário delinear uma educação superior capaz de fornecer as bases da inovação, da competitividade e da produtividade

3 Essa integração econômica e política foi acordada por 27 Estados-membros da Europa, aos quais outros se uniram posteriormente. 
(BASTOS, 2009) e de que um comércio comum requeria uma formação única, surgiu a ideia de um Espaço Europeu de Ensino Superior, ou EEES (RIEDO; PEREIRA, 2009). O argumento que enfatizava a importância da integração dos sistemas nacionais de educação superior em um sistema único era o de que as IES deveriam assumir a missão de preparar a mão-de-obra adequada para atuar em qualquer país europeu. Afinal, a globalização, ao menos no discurso, envolve também a "livre mobilidade de recursos humanos". Nesse sentido, em 1999, 29 países assinaram o documento da Declaração de Bolonha ${ }^{4}$.

O conhecido Processo de Bolonha, hoje abrangendo mais de quarenta países europeus, apresentava seis áreas de atuação e buscava ser um instrumento de coordenação e de europeização de políticas (públicas) educativas (ANTUNES, 2007). Mais que isso, seu escopo seria uma sólida convergência na educação europeia, a fim de que esta respondesse adequada e eficientemente aos problemas, oportunidades e desafios gestados pela globalização da economia.

De acordo com Riedo e Pereira (2009), os principais objetivos do Processo de Bolonha são: a promoção do sistema de Ensino Superior Europeu, inclusive em nível mundial; a busca de uma harmonização entre os sistemas universitários, que facilitaria o reconhecimento de títulos de formação superior entre os países e ampliaria a oferta de profissional altamente qualificado disponível no mercado de trabalho; e "o estímulo à mobilidade de estudantes, docentes e profissionais entre os países participantes, propiciando o intercâmbio de experiências e conhecimentos e que contribuiria para acelerar o desenvolvimento econômico e cultural de cada país" (p. 61).

Para Bastos (2009), o Espaço Europeu de Educação Superior tem como finalidade alcançar os seguintes objetivos: a) aumentar a competitividade e a atratividade em nível internacional à educação superior europeia; b) melhorar a adaptação da formação dos graduados europeus às demandas do mercado de trabalho; d) desenvolver a mobilidade interna e externa de alunos. Uma das metas é estabelecer um sistema uniforme de créditos, organizado a partir de ciclos de estudos. A lógica do Processo de Bolonha é justamente ser um coadjuvante das estratégias empreendidas pela União Européia no que diz respeito à educação superior.

4 O início desse debate remete à Declaração de Sorbonne (de 25 de Maio de 1998), que deu início à criação de uma Área Européia de Ensino Superior como um mecanismo para promover a mobilidade de alunos e docentes, possibilitar a empregabilidade dos cidadãos europeus e o desenvolvimento econômico e social da Europa. Além disso, segundo Dias Sobrinho (2005), o processo de Bolonha foi uma iniciativa governamental que inicialmente foi adotada apenas pelos ministros da área educacional. Somente em 2002, em Lisboa, o processo foi assumido como uma estratégia global entrando na agenda política da União Europeia. 
A despeito de certo otimismo relativo à mobilidade de estudantes, pesquisadores e docentes, a lógica dessa "harmonização" entre os sistemas universitários e da uniformização dos currículos, além do forte vínculo que se visa construir entre a formação e as demandas do mercado são alguns aspectos que vêm sendo amplamente debatidos na comunidade europeia e também por estudiosos de outros países temerosos com a propagação do processo de Bolonha aos outros países.

Dias Sobrinho (2009) aponta duas críticas fundamentais a esse processo: o primeiro se refere a sua excessiva centralização. A reforma foi estruturada de cima para baixo, com pouca participação da comunidade universitária e passando por cima da autonomia das universidades. A segunda crítica diz respeito às funções essenciais da educação superior. $\mathrm{O}$ autor coloca que se o

mercado determinar a formação universitária, impondo currículos de curta duração e voltados ao atendimento das necessidades laborais e às características dos empregos do momento, muitos da comunidade científica temem que a universidade perca suas perspectivas de longo prazo e se afaste das referências sociais (p. 144).

Já Gianquinta e Guerraggio (2006 apud RIEDO; PEREIRA, 2009) compreendem que o mercado tende a

favorecer a formação profissional e a aplicação prática do conhecimento, tal visão de universidade estaria levando a um redimensionamento do momento teórico, penalizando-o, sub-avaliando-o, marginalizando-o e comprometendo toda a formação universitária (p. 58).

Além disso, Dias Sobrinho (2009) reforça que essas relações de cooperação detêm um forte caráter utilitarista. Ou seja, os intercâmbios pouco têm do sentido da tradicional solidariedade universitária ou de uma cooperação visando somente o desenvolvimento da ciência universal e desinteressada. $\mathrm{O}$ autor ressalta que, ainda que não de forma absoluta, "nas relações entre sistemas, instituições, professores e estudantes dos distintos países, o que prevalece mesmo é o critério de utilidade" (p. 144). Essa integração impõe certa homogeneização do currículo e, por sua vez, a perda das funções essenciais da educação superior.

Prosseguindo nessa direção, Dias Sobrinho (2009, p. 145) argumenta que

os esforços que estão sendo feitos no sentido de aumentar a convergência da educação superior esbarram em tensões e contradições bastante fortes. De um lado, a crescente pressão por aumentar a competitividade e aumentar os vínculos da educação superior com 
o mercado e as necessidades laborais. Por outro lado, a defesa dos valores acadêmicos e da função política de democratização. A visão da educação como bem público orientado para a produção de bemestar da população está coerente com o reforço também explícito dos valores acadêmicos, em contraposição aos interesses individualistas do mercado. Esta tensão não é particularmente restrita à Europa, pois, faz parte das transformações da sociedade global e da educação superior de todas as partes, guardadas as peculiaridades e diferenças de um país a outro.

$\mathrm{O}$ atendimento desses interesses utilitaristas e da homogeneização requer padronização nas informações, nas avaliações e nas prestações de contas. Nesse sentido, foi notória a adoção da prestação de contas ${ }^{5}$ focada em objetivos, categoria específica reforçada pelas diretrizes neoliberais, pelo grupo de decisão da EEES.

No que se refere à ênfase à prestação de contas, Antunes (2007) reconhece uma forte inspiração nos mandamentos da Nova Gestão Pública. É perceptível uma preocupação em estabelecer indicadores de realização, gráficos de consecução, cartões de resultados (scorecards), listas e tabelas de desempenho comparado, em suma, uma impressionante produção de instrumentos, procedimentos e metodologias de controle, por parte de entidades extra-nacionais. Nada contra a prestação de contas e procedimentos e metodologias de controle, mas é evidente a preocupação em quantificar informações que ainda nem foram discutidas a fim de avançar com o processo.

A reestruturação do currículo tem como discurso legitimador a possível "comparabilidade de formações diferentes para efeitos de reconhecimento internacional e de mobilidade, de transparência da melhoria efetiva da qualidade das formações" (BASTOS, 2009, p. 157). Para isso, a estrutura acadêmica curricular passa a ser alterada e dividida em três ciclos: o primeiro, básico, é com três anos de duração, seguido de uma formação profissional de até três anos e um doutorado para aqueles que quiserem dedicar-se à pesquisa.

Bastos (2009) aponta que esse sistema de ciclos ratifica um esquema perverso no qual o mercado, caso esteja interessado em relações de trabalho mais flexíveis e diminuição dos custos de mão-de-obra, contrata o estudante que concluiu apenas o primeiro ciclo de formação superior graduada. Isso auxiliará o mercado e a promoção da competitividade europeia. E, ao mesmo tempo, o Estado diminuiu os encargos públicos com a educação superior, tornando-se assim, resultados práticos das políticas neoliberais.

5 Ver mais em Afonso (1998). 
Essas mudanças no âmbito da educação superior na Europa tende a alterar completamente, segundo Bastos (2009), uma das grandes vantagens competitivas da Europa: a diversidade de estruturas de graus, diferenciação nos períodos de estudos, diversas formas de acesso, etc.

\section{A AMÉRICA LATINA E O PROCESSO DE COMODITIZAÇÃO DA EDUCAÇÃO SUPERIOR}

As políticas de liberalização e desregulação financeira e do trabalho adotadas pelos países latino-americanos marcaram o final da década de 1980 e início da década de 1990. Como parte dessas políticas, os sistemas nacionais de educação superior da América Latina - pressionado pelo contexto competitivo da onda globalizante ${ }^{6}$ e acompanhando a tendência mundial de reformas neoliberais - se viram forçados a realizar mudanças.

Essas mudanças educacionais - tidas como "reformas modernizadoras" foram fortemente incentivadas pelos organismos multilaterais, em especial o Banco Mundial ${ }^{7}$. A prescrição deste órgão para a educação buscava:

novas formas de regulação e gestão das instituições estatais, que permitam alterações e arranjos jurídico-institucionais, visando a busca de novas fontes de recursos junto a iniciativa privada sob o argumento da necessária diversificação das fontes de recursos; 4) a aplicação de recursos públicos nas instituições privadas; [...] 5) diversificação do ensino superior, por meio do incremento à expansão do número de instituições não-universitárias; entre outras (DOURADO, 2002, p. 240).

A implementação das diretrizes mais amplas de reforma ideológica na reforma educacional visava, no curto prazo, a diminuição dos subsídios para a ciência e pesquisa, o controle seletivo do Estado na distribuição de recursos financeiros, a expansão das instituições e das matrículas privadas, a promulgação de leis de educação superior e a criação de órgãos para avaliar as instituições universitárias (MOLLIS, 2008). E, como objetivo de médio prazo, a educação latino-americana aumentaria sua eficiência e se adequaria enquanto instrumento do desenvolvimento econômico.

Assim como nos outros países, Dourado (2002, p. 238) ressalta que "uma nova orientação para a articulação entre educação e produção do conhecimento,

6 Ver mais em Oliveira (2009).

7 Dourado (2002) ressalta que a atuação do Banco Mundial no âmbito das políticas educacionais indicava o seu papel de interlocutor da política macroeconômica do Fundo Monetário Internacional (FMI). 
por meio do binômio privatização e mercantilização da educação" passou a dar a tônica desse processo.

Nessa perspectiva, os debates referentes à mudança ocorrida nos sistemas de educação superior latino-americanos abordam, principalmente, a ocorrência e os efeitos de dois processos desencadeados nessa região. O primeiro se refere à tendência mercantilizante e utilitarista da universidade pública, em decorrência - poder-se-ia dizer - daquela ocorrida nos países centrais. O segundo está relacionado ao processo de comoditização da educação privada, enquanto reflexo da expansão das universidades privadas. Consequentemente, são esses os temas mais debatidos pela literatura dedicada à educação superior na região.

O primeiro processo abarca inúmeras questões que não pretendemos esgotar neste trabalho. Entretanto, a fim de ilustrar a dinâmica do processo de mercantilização da universidade pública, apresentaremos elementos que fornecem evidências acerca da lógica por trás da aproximação entre esse ator e o mercado. Aproximação esta que se estende tanto à incorporação das demandas da agenda de pesquisa da empresa privada e de um ensino pró-mercado, quanto aos mecanismos de gestão gerencial (similar à das empresas privadas) e de captação de recursos por parte dessas universidades.

A partir da década de 1980, a política de ciência e tecnologia (PCT) - intrinsecamente vinculada ao complexo público de educação superior latinoamericana - gradualmente incorporou elementos associados à empresa privada (DAGNINO, 2007). Rodríguez (1997) chamou a utilização desse conjunto de elementos na PCT de "enfoque gerencial". Este, por sua vez, está relacionado às construções teóricas da matriz "evolucionária", associada à corrente da Economia da Inovação (DIAS, 2005).

A característica principal dessa matriz é, justamente, a atribuição do papel central dentro do processo de desenvolvimento econômico e social à inovação tecnológica. Sendo a inovação um processo diretamente relacionado à empresa privada, esta última passa, automaticamente, a ser entendida como o ator central das atividades de ciência e de tecnologia e, portanto, como ator fundamental envolvido com as ações da PCT (SERAFIM, 2008). Nesse sentido, o mercado passou a ser utilizado como critério básico de definição de necessidades e prioridades.

Com a relativa redução do papel do Estado na PCT, como os processos de privatização e de sucateamento de alguns institutos públicos de pesquisa, por exemplo, a universidade passou a ocupar, sem incremento no orçamento, o espaço central dentro da relação pesquisa-produção. As universidades públicas tiveram que se adequar e impulsionar mecanismos de captação de recursos via 
parceira com empresas. É a partir desse momento que a universidade passa a defender a agenda da empresa, papel antes desempenhado pelos institutos públicos de pesquisa (DAGNINO; NOVAES, 2006).

O entendimento de que inovação tecnológica é elemento essencial no desenvolvimento econômico, como já vimos anteriormente, conformou a necessidade de criação de novos padrões de financiamento, gestão e alocação de recursos, ofertista-linear em sua essência. Um claro exemplo disso, no caso do Brasil, foi a instituição dos Fundos de Apoio ao Desenvolvimento Científico e Tecnológico (Fundos Setoriais ${ }^{8}$ ) em 1999 pelo Governo Federal. Os recursos desses fundos são provenientes, em grande parte, dos próprios setores específicos, que são ao mesmo tempo contribuintes e usuários. Essa política de estímulo "forçado" ao desenvolvimento tecnológico empresarial através de novos mecanismos de fomento viabilizou a aproximação da universidade pública ao mercado 9 .

O caso do Brasil ilustra, em linhas gerais, algumas das principais tendências atuais das universidades públicas latino-americanas. O que se nota é que, de forma quase que inconsciente e aparentemente desarticulada, essas universidades têm atuado no sentido de reforçar e consolidar um modelo reducionista, pautado nos interesses mercantis da empresa (reconhecido como o único ator da sociedade passível de interação) e na lógica gerencial e utilitarista, no âmbito do ensino superior e da pesquisa universitária.

O discurso adotado pelas universidades públicas, a partir desse momento, foi de que a inovação era um elemento importante para o desenvolvimento econômico. E que as universidades deveriam ser disseminadoras de uma cultura inovadora e uma forte geradora do elo entre ela e as empresas. Aliado a isso, o discurso da eficiência, da gestão racional, da produtividade, da qualidade, da excelência, amplamente divulgado pelo Banco Mundial e outros organismos multilaterais, totalmente sincronizados com as orientações neoliberais e da nova administração pública, foi ganhando cada vez mais corpo e adeptos.

No que se refere à mudança relacionada às principais formas de gestão das universidades públicas, quatro aspectos são importantes de apresentar: 1 . Forte preocupação com o princípio de accountability (prestação de contas) e com a "melhoria" da qualidade da universidade; 2. Aumento dos rankings e da padronização dos sistemas de avaliação da educação superior; 3. Criação de instâncias específicas a fim de desburocratizar alguns mecanismos de contratação e de "caça" a novos contratos; 4. Aumento das terceirizações e da precarização do trabalho.

8 A proposição e implementação dos Fundos ocorreram de forma simultânea à privatização e à desestatização de diversos setores controlados pelo Estado no governo Fernando Henrique Cardoso (1994-2002).

9 Ver mais em Dias (2009) 
A compreensão de que as instituições de educação superior são ferramentas prioritárias para o desenvolvimento, o progresso e a prosperidade econômica, pressionou-as para o alcance de resultados quantitativos e passíveis de serem trabalhados pelo mercado. Mollis (2008) coloca que o entendimento é de que pela 'salvação econômica' de nossos pobres países subdesenvolvidos, de acordo com as projeções das agências bancárias internacionais, as universidades públicas deveriam prestar contas a fim de se observar possíveis desvios da função de potencializadoras do desenvolvimento.

Nesse sentido, o discurso de "melhoria da qualidade", entendida como um fator econômico, gradativamente passou a ganhar visibilidade. As universidades, em busca dessa suposta qualidade (de caráter universal), passaram a adotar índices e escalas quantitativas, ignorando as especificidades de cada área e do próprio processo de construção e disseminação do conhecimento como algo não passível de quantificação, coerentes com esse discurso. Este entende "melhoria da qualidade" como um fator pró-mercado e inerente a essa relação com ele. Ou seja, reforçar a relação com o mercado e adotar mecanismos de gestão relacionadas às práticas da empresa são elementos que levariam a uma melhora, portanto, da qualidade da universidade.

Seguindo semelhante orientação, a comunidade de pesquisa ${ }^{10}$, por meio de órgãos de fomento nacionais, passou a configurar sistemas de avaliação condizentes com as tendências mundiais, como por exemplo, índices de citação e de periódicos, rankings, etc.

Os sistemas de avaliação, incrementados pelas práticas gerenciais, deixaram de visar à regulação e ao controle estatal, como ocorria, para focar em critérios que espelhassem a produtividade das tarefas, em especial, às atividades de pesquisa e pós-graduação. Esses critérios, segundo Dias Sobrinho (2010), são baseados em parâmetros internacionais que, por sua vez estão atrelados aos determinantes econômicos, definem o conceito de "qualidade" e de "boas práticas".

As agências multilaterais, com a colaboração de agências regionais e nacionais, "elaboram e põem em prática um arsenal de instrumentos supranacionais de controle e de certificação" (DIAS SOBRINHO, 2010, p. 272). Um exemplo disso remete à Organização para a Cooperação e Desenvolvimento Econômico (OCDE) que, segundo o autor, define os instrumentos, os indicadores, as metodologias e os objetivos de avaliação. O objetivo desse controle supranacional é "atestar aos clientes e interessados em geral que uma instituição cumpre ade-

10 Denominamos aqui de comunidade de pesquisa pois é ela que compõe cargos altos dos órgãos de fomentos e, por sua vez, formulam os sistemas nacionais de avaliação. 
quadamente esses padrões e seguem corretamente a norma pré-estabelecida" (DIAS SOBRINHO, 2010, p. 272). Ao seguir essas normas, os sistemas nacionais - e é o caso dos países da América Latina - serão acreditados por essas agências e, portanto, acessarão possíveis benefícios. Nesse sentido, portanto, as agências supranacionais adquirem importância fundamental na disseminação das ideias de mercantilização e comoditização da educação superior, funcionais ao corrente projeto neoliberal.

Em relação à criação de instâncias, uma iniciativa que nos exemplifica essa situação se refere à criação do Grupo Gestor de Programas Educacionais (GGPE) ligado à reitoria da Universidade Estadual de Campinas (Unicamp). Esse grupo, instituído em 2005, tem como objetivo gerenciar ações de cooperação entre a Unicamp e outras instituições, a fim de facilitar e estimular essas ações de cooperação. Primeiramente, esse grupo buscava desenvolver projetos educacionais no sentido da formação continuada, tendo posteriormente ampliado o seu escopo. De acordo com o próprio site da $\mathrm{GGPE}^{11}$, sua instituição ocorreu a partir da evolução observada nos últimos anos, em várias unidades de ensino da Universidade, de grupos que intensificaram suas ações de extensão. Os docentes "necessitavam interagir administrativamente com as Instituições públicas e privadas de forma a oferecer os seus projetos e participar dos diversos certames lançados para a contratação e prestação de serviços educacionais". Nesse sentido, esse grupo faz papel de elo entre esses docentes e o mercado. Ele busca convênios e contratos, prospectando, customizando, participando de licitações públicas estaduais, municipais, federais, e instituições da iniciativa privada. Esse grupo é um exemplo da união universidade-mercado.

Um último aspecto que se observa se refere aos processos de terceirização de determinadas atividades conduzidas no âmbito das universidades. Marcelino (2008) define terceirização como um processo de contratação de trabalhadores por uma empresa interposta cujo objetivo final é a redução de custos com a força de trabalho. Nessa relação de contratação, há sempre uma outra empresa auferindo ganhos através dessa intermediação da força de trabalho.

O processo de terceirização observado, por exemplo, na Unicamp, pode ser enquadrado em duas categorias: uma se refere à contratação de pessoal para serviços gerais, limpeza, segurança e etc. e a outra se refere à contratação via Fundação de serviços especializados. A primeira categoria já vem sendo observada na Unicamp há algum tempo. Os serviços de limpeza e de segurança desde o final dos anos 1990 são serviços contratados com alta rotatividade e mobilidade da mão-de-obra. No que diz respeito à segunda categoria, esta tem

11 Informações obtidas em http://www.ggpe.prpg.unicamp.br/pag_historico.htm. 
um caráter diferenciado. Ao contrário do que se dizia, as terceirizações deixaram de estar apenas em atividades-meio para se espraiarem nas atividades-fim. A Universidade avançou nas terceirizações via Fundação da Unicamp (Funcamp) no sentido de terceirizar até a contratação de pesquisadores.

Sguissardi (2010) argumenta que, enquanto a graduação passa pelo processo de mercantilização, as "universidades de pesquisa" (pós-graduação) passam por um processo de intensificação e precarização do trabalho docente. A academia, segundo o autor, vem passando por uma "crise da profissão acadêmica". Os professores estão sendo estimulados, por conta de todo o processo de mercantilização da educação, a serem "empresários do conhecimento", trabalhando como consultores para terem complementação salarial. Isso está ocorrendo propositadamente por conta da flexibilização do regime de trabalho em tempo integral e da multiplicação das fundações de apoio institucional de natureza privada no espaço público.

O produtivismo acadêmico, fomentado pelos modelos de avaliação implementados na América Latina, é um fator importante na intensificação e precarização do trabalho dos professores universitários. Esse produtivismo decorre da excessiva valorização da quantidade em relação à qualidade e das consequências perversas desta valorização sobre as atividades de ensino, orientação e extensão, entre outras, que induzem à uniformidade e à competitividade (SGUISSARDI, 2010).

O outro processo que pretendemos destacar aqui diz respeito à orientação privatista do campo educacional e, em sua pior demonstração, à comoditização da educação superior. A diretriz do Banco Mundial em repassar as funções educacionais ao setor privado, em especial nos casos em que o Estado não consegue ampliar o acesso às universidades, pode ser observada de forma acentuada, principalmente, em países como Chile e Brasil.

No caso do Brasil, Oliveira (2009) ressalta que a atuação legal do setor privado na educação nos remete à Constituição de 1988, que explicitou a existência de escolas com fins lucrativos. Entretanto, seu crescimento foi acelerado somente a partir da regulamentação da Lei de Diretrizes e Bases (LDB), em 1996. Foi nesse mesmo período que o número de instituições privadas começou a crescer sistematicamente.

Groppo (2011) ressalta que a LDB permitiu a criação de cursos sequenciais por campo de saber (mas cujo diploma não equivale ao de graduação), reduziu a exigência de qualificação do corpo docente e em regime de dedicação integral em "relação ao projeto original da LDB (1/3 em vez da metade), e manteve ainda indefinida a regulamentação da autonomia universitária das universidades federais, em especial sobre o financiamento federal" (p. 51). 
A expansão do setor privado na educação (de 1995 a 2002, expansão de $160 \%$ de cursos superiores privados ${ }^{12}$ ) e a sua entrada no mercado de capitais tiveram como efeito o crescimento de conglomerados de empresas e holdings interessados em investir nesse setor. As transações na bolsa de valores relacionadas aos conglomerados da educação (no caso do Brasil, temos como exemplos os grupos COC, Positivo, Pitágoras, etc.) demonstram o ritmo de expansão das "instituições com fins lucrativos, particularmente aquelas suportadas por fundos de investimento e/ou ações na bolsa de valores" (OLIVEIRA, 2009, p. 751).

Oliveira (2009), citando informações fornecidas pela KPMG Consultoria, revela que em 2007 ocorreram 19 aquisições e em 2008, de janeiro a setembro, 41. Em 2009, algumas aquisições foram efetuadas, mas o ritmo diminuiu em função da crise mundial, concentrando poder nas mãos de grupos maiores que possuem maior poder de compra que as instituições mais frágeis. Esses fundos de investimento têm condições de injetar altas quantias em empresas educacionais, ao mesmo tempo em que

empreendem ou induzem processos de reestruturação das escolas nas quais investem, por meio da redução de custos, da racionalização administrativa, em suma, da "profissionalização" da gestão das instituições de ensino, numa perspectiva claramente empresarial. Essa perspectiva racionalizadora é fundamentalmente orientada para a maximização de lucros, chegando ao paroxismo em algumas situações (OLIVEIRA, 2009, p. 743).

Aliado a isso, esses conglomerados reforçam também a flexibilização no currículo, ao introduzir novas tecnologias para o oferecimento de atividades não-presenciais. A "necessidade" de redução de custos da atividade-fim de uma instituição de ensino motivou a introdução de tecnologias/metodologias de educação à distância (EAD), para redução em até $20 \%$ da carga horária presencial, e de adoção para tratar referentes à modalidade interdisciplinar, que proporciona uma economia em maior escala do que a obtida com a substituição de disciplinas, bem como um maior ganho na qualidade acadêmica do curso. Esse é o caso da Hoper Consultoria Acadêmica (OLIVEIRA, 2009). Claramente, esse processo reconhece da pior forma possível que educação é uma mercadoria ou, como aponta o autor, uma commodity.

12 Essa expansão correspondeu ao aumento de 3.500 para 9.100 de cursos (GROPPO, 2011). 
De acordo com Dias Sobrinho (2005, p. 209), a educação superior latinoamericana paulatinamente por esses processos foi perdendo o seu

significado histórico de patrimônio social e sustentáculo da cidadania e do desenvolvimento nacional e adquirindo funções que coincidem com os interesses de inserção das corporações econômicas à globalização neoliberal.

O balanço realizado por Mollis (2008) sobre essas reformas é de que as universidades tiveram alterada sua identidade como instituições de saber e caminharam rumo à construção de uma nova identidade que se assemelha a um "supermercado", no qual os estudantes são tratados como consumidores ou clientes, o saber como mercadoria e o professor como um assalariado. Por meio desse processo perverso, a lógica da universidade e do conhecimento passa a se aproximar cada vez mais daquela "do mercado".

\section{CONSIDERAÇÕES FINAIS}

A ascensão do neoliberalismo enquanto ideologia de atuação do Estado motivou a implementação do enfoque gerencial nas instituições de educação superior. Mais que isso, ela reforçou a ideia de que seria por meio da interação dessas instituições com o setor produtivo que o progresso econômico dos países - via inovação tecnológica ou capacitação de mão-de-obra para o mercado - se instauraria novamente. Entretanto, o sistema global de produção, fortemente dependente de inovação, precisando de mecanismos flexíveis e de grande adaptabilidade à competitividade, reconhece que não basta a qualificação para o trabalho. É necessário que essas IES compreendam a prerrogativa de continuamente desenvolver "possibilidades de aprendizagem e adaptar-se perante as mudanças dos conhecimentos e as novas demandas do trabalho e da vida social" (DIAS SOBRINHO, 2005).

Para isso, portanto, a educação deveria passar por uma reforma. Dias Sobrinho (2005, p. 169) corrobora que "as reformas educacionais se tornam imperativas quando surgem ou se agudizam problemas nas estruturas econômicas, sociais e políticas que requerem soluções urgentes".

O panorama mundial da educação superior está tendendo a aceitar que o conhecimento deve visar utilidade prática e rápida e que as universidades devem se assemelhar cada vez mais a uma lógica empresarial. Esse quadro nos coloca diante de uma crise de identidade enquanto sociedade e de uma disputa de projetos políticos. 
Uma tentativa de reverter esse quadro, segundo Dourado (2002) é construir formas de resistência - ainda que pontuais - a esse movimento pró-mercado, com a articulação entre amplos setores da sociedade, em defesa de um projeto de nação, em primeiro lugar, e de um projeto de educação superior pública que realmente venha cumprir com o seu papel de caráter público. Enquanto outros setores da sociedade não se manifestam, o embate dependerá em grande medida da própria academia. Tendo em vista que a universidade não é um bloco monolítico, a esperança é de que grupos de pesquisadores venham a crescer, conjuntamente com a conscientização dos movimentos sociais, e a resistir a esse processo de mercantilização que vem engendrando nas bases da educação superior mundial.

\section{REFERÊNCIAS}

AFONSO, Almerindo J. Políticas educativas e avaliação educacional. Braga: Universidade do Minho, 1998.

ANTUNES, Fátima. O Espaço europeu de ensino superior para uma nova ordem educacional? ETD - Educação Temática Digital, Campinas, v. 9, n. esp., p.1-28, dez. 2007.

BASTOS, Carmem C. Barradas Correia. O Processo de Bolonha no espaço europeu e a reforma universitária brasileira. In: PEREIRA, Elisabeth Monteiro de Aguiar; ALMEIDA, Maria de Lourdes Pinto (Org.). Universidade contemporânea. Políticas do processo de Bolonha. Campinas: Mercado das Letras, 2009. p. 155-164.

BELLUZZO, Luiz Gonzaga. As transformações da economia capitalista no pós-guerra e a origem dos desequilíbrios globais. In: CARNEIRO, Ricardo (Org.). A supremacia dos mercados e a política econômica do governo Lula. São Paulo: Editora UNESP, 2006.

BOK, Derek. Universities in the marketplace: the commercialization of Higher Education. Princeton: Princeton University Press, 2003.

CASTELLS, Manuel. The information age: economy, society and culture. 2. ed. Malden: Blackwell, 2000. v. 3.

CHESNAIS, François. A mundialização do capital. São Paulo: Xamã, 1996. 
DAGNINO, Renato Peixoto; NOVAES, Henrique Tahan. Construindo uma nova agenda para a Política Científica e Tecnológica: uma discussão sobre a neutralidade da ciência e o determinismo tecnológico.In: ENCONTRO ANUAL DA ANPOCS - ASSOCIAÇÃO NACIONAL DE PÓS-GRADUAÇÃO E PESQUISA EM CIÊNCIAS SOCIAIS, 30. 2006, Caxambu-MG. Anais... (CD Rom), Caxamvu-MG, 2006.

DAGNINO, Renato Peixoto. Ciência e tecnologia no Brasil: o processo decisório e a comunidade de pesquisa. Campinas: Editora da Unicamp, 2007.

DIAS, Rafael de Brito. A política científica e tecnológica latinoamericana: relações entre enfoques teóricos e projetos políticos. 2005. 106 p. Dissertação (Mestrado) - Universidade Estadual de Campinas, Campinas, 2005.

DIAS, Rafael de Brito. A trajetória da política científica e tecnológica brasileira: um olhar a partir da Análise de Política. 2009. 237 p. Tese (Doutorado) - Universidade Estadual de Campinas, Campinas, 2009.

DIAS SOBRINHO, José. Dilemas da educação superior no mundo globalizado: sociedade do conhecimento ou economia do conhecimento? São Paulo: Casa do Psicólogo, 2005.

DIAS SOBRINHO, José. O Processo de Bolonha. In: PEREIRA, Elisabeth Monteiro de Aguiar; ALMEIDA, Maria de Lourdes Pinto (Org.). Universidade contemporânea. Políticas do processo de Bolonha. Campinas: Mercado das Letras, 2009. p. 131-154

DIAS SOBRINHO, José. Acreditação da Educação Superior. In: LÓPEZ SEGRERA, Francisco; RIVAROLA, Domingo (Orgs.). La universidad ante los desafíos del siglo XXI. Assunção: Centro Paraguayo de Estudios Sociológicos, 2010. p. 261-294

DOURADO, Luis Fernandes. Reforma do Estado e as políticas para a educação superior no Brasil nos anos 90. Educ. Soc., Campinas, v. 23, n. 80, p. 234-252, set. 2002.

FOUCAULT, Michel. Discipline and punish: the birth of the prison. New York: Vintage, 1977.

FOUCAULT, Michel. Power/Knowledge: selected interviews \& other writings 1972-1977. New York: Pantheon, 1980. 
GIANQUITA, Mariano; GUERRAGGIO, Angelo. Ipotesi sull'università. Torino: Codice, 2006.

GROPPO, Luís Antonio. Da universidade autônoma ao ensino superior operacional: considerações sobre a crise da universidade e a crise do Estado nacional. Avaliação, Campinas; Sorocaba, v. 16, n. 1, p.37-55, mar. 2011.

HARVEY, David. Breve historia del neoliberalismo. Madri: Ediciones Akal, 2007.

MANN, Michael. The sources of social power. Cambridge: Cambridge University Press, 1986.

MARCELINO, Paula Regina Pereira. Terceirização e ação sindical. A singularidade da reestruturação do capital no Brasil. 2008. 373p. Tese (Doutorado) - Universidade Estadual de Campinas, Campinas, 2008.

MOLLIS, Marcela. Identidades alteradas: de las universidades reformistas a las universidades de la reforma. In: BERNHEIM, Carlos Tünnermann (Ed.). La educación superior en América Latina y el Caribe: diez años después de la Conferencia Mundial de 1998. Cali: Iesalc-Unesco, PUJ, 2008.

MORAES, Reginaldo. Neoliberalismo: de onde vem, para onde vai? São Paulo: Editora SENAC, 2001.

OLIVEIRA, Romualdo Portela de. A transformação da educação em mercadoria no Brasil. Educ. Soc., Campinas, v. 30, n.108, p. 739-760, out. 2009.

POCHMANN, Márcio. Processo de exclusão e construção do sistema único de inclusão social no Brasil. Disponível em: < http://unpan1.un.org/intradoc/ groups/public/documents/un/ unpan007618.pdf>. Acesso em: jan. 2008.

POLANYI, Karl. A grande transformação: as origens de nossa época. Rio de Janeiro: Editora Campus, 2000.

RIEDO, Cássio Ricardo Fares; PEREIRA, Elisabete Monteiro de Aguiar. O processo de bolonha e suas conseqüências na Itália. In: PEREIRA, Elisabeth Monteiro de Aguiar; ALMEIDA, Maria de Lourdes Pinto (Org.). Universidade contemporânea. Políticas do processo de Bolonha. Campinas, SP: Mercado das Letras, 2009. p. 59-80. 
RODRÍGUEZ, Rosendo Diaz. Ofertismo em ciência, fluxo acrítico de tecnologias forâneas e enfoque gerencial: uma problematização da política científica e tecnológica cubana. 1997. 134 p. Dissertação (Mestrado) Universidade Estadual de Campinas, Campinas, 1997.

SERAFIM, Milena Pavan. A política científica e tecnológica e a política de inclusão social: buscando convergência. 2008. 138 p. Dissertação (Mestrado) - Universidade Estadual de Campinas, Campinas, 2008.

SGUISSARDI, Valdemar. Mercantilização e intensificação do trabalho docente. Traços marcantes da expansão universitária brasileira hoje. In: LÓPEZ SEGRERA, Francisco; RIVAROLA, Domingo (Orgs.). La universidad ante los desafíos del siglo XXI. Assunção: Centro Paraguayo de Estudios Sociológicos, 2010. p. 295-316

SLAUGHTER, Sheila; LESLIE, Larry. Academic capitalism: politics, policies and the entrepreneurial university. Baltimore: The Johns Hopkins University Press, 1997.

SLAUGHTER, Sheila; RHOADES, Gary. Academic capitalism and the new economy: markets, state and higher education. Baltimore: The Johns Hopkins University Press, 2004.

WILLIAMSON, John. Reformas políticas na América Latina na década de 80. Revista de Economia Política, São Paulo, v. 12, n. 1, 1992. 
